\title{
Will assessment and Incentives Help Improve the Level of Urban Public Services? ——Empirical Evidence from the Selection of "Civilized Cities"
}

\author{
Hang Xiao ${ }^{1}$ \\ ${ }^{1}$ Institute of Finance and Economics, Shanghai University of Finance and Economics \\ Email: xiaohang@163.sufe.edu.cn
}

\begin{abstract}
The creation of a "civilized city" is an important measure to realize the simultaneous development of urban material civilization and spiritual civilization, promote the innovation of urban management mode, and realize the sustainable development of the city. Enhancing the happiness of urban residents, improving the basic public level of the city, and making urban life more convenient and quality is one of its main goals. Based on the panel data of 102 prefecture-level and above major cities across the country from 2009 to 2017, this paper uses the PSM-DID method to comprehensively examine the characteristics of the impact of the selection of "civilized cities" on the improvement of urban public services and its mechanism. The research results show that the selection of "civilized cities" can effectively improve the level of urban public services; it mainly improves the level of urban basic public services by changing the structure of local government fiscal expenditures and affecting land prices; the scale of urban population and economic scale affects the above-mentioned Policy effects have significant heterogeneous effects. This article provides empirical support for the selection of "civilized cities" to effectively improve the level of urban basic public services, and provides ideas for further innovation in urban management models.
\end{abstract}

Keywords: civilized city, urban basic public service level, double difference

\section{考核激励有助于改善城市公共服务水平吗？一一来自 “文明城市”评选的经验证据}

\author{
肖航 ${ }^{1}$
}

\section{1 上海财经大学财经研究所}

Email: xiaohang@163.sufe.edu.cn

\section{摘要}

“文明城市”创建是实现城市物质文明与精神文明同步发展，推进城市管理模式创新，实现城市可持续发展的重 要举措。增强城市居民的幸福感，提升城市基本公共水平，让城市生活更便捷、更有质量是其主要目标之一。 本文基于 2009-2017 年全国 102 个地级及以上主要城市的面板数据，运用 PSM-DID 方法全面考察了“文明城 市”评选对城市公共服务水平提升的影响特征及其作用机制。研究结果表明“文明城市”评选可以有效提升城市 公共服务水平; 其主要通过改变地方政府财政支出结构、影响土地价格这两种路径，进而改善城市基本公共服 务水平; 城市人口规模和经济规模对上述政策效应具有显著的异质性影响。本文为“文明城市”评选可以有效改 善城市基本公共服务水平提供了实证支持，为进一步创新城市管理模式提供了思路。

关键词: 文明城市; 城市基本公共服务水平; 双重差分 


\section{1.前言}

在过去四十年, 中国经历了经济高速增长的过 程，GDP 年平均增长率高达 $9.5 \%$ ，成为“世界工厂”。 在“锦标赛”的考核竞争模式下，地方政府也倾向于用 短期的经济增长取代更为长期的目标 (周黎安, 2007），出现高房价、污染和拥堵等“城市病”。2003 年，中央精神文明建设指导委员会印发了《中央精神 文明建设指导委员会关于评选表彰全国文明城市、文 明村镇、文明单位的暂行办法》（文明委 2003 年 9 号），从而在全国范围内正式启动了“文明城市”的评 选活动。同时, 由中央文明委下发的《全国文明城市 测评体系 (试行) 》（文明委 2004 年 7 号）对评选 的前提条件、考核指标进行了清晰界定。“文明城市” 考核体系对学校教育、城市文体设施、公共设施与公 共交通、医疗与公共卫生、环境保护等民生型公共服 务方面都有较高的要求。在中国特有的“以土地谋发 展”模式下，地方政府为了辖区经济增长，积极进行 各种园区建设、新城开发, 加强基础设施投资, 以便 能够获取巨大的土地财政收入; 另一方面以成本价、 甚至“零地价”积极开展“土地引资”，通过低价工业用 地吸引企业, 带动地方经济发展 (刘守英等, 2012)。 由于经济型公共服务 (例如道路等基础设施建设) 能 够提升土地价值，地方政府为了获得更多的土地出让 收入必然会努力增加经济型公共物品提供（李娟娟、 宋琪，2018），而民生类公共服务供给则相对较弱。 两种土地利用模式, 可以反映出地方政府公共服务供 给偏好, “土地引资征税”目的在于吸引企业进入，从 而获得税收收入, 公共服务对象是企业, 则以经济型 公共服务为主; “招拍挂”土地多为住宅、商业用地, 由于用地价格较高, 住商用地出让还肩负为地方公共 服务支出筹资的功能。而且住宅、商业用地所需要的 公共服务则更为复杂, 例如配套的学校、医院、绿化 等等。如果参与“文明城市”评选后, 城市工业用地价 格上涨、商业用地价格下降, 说明地方政府有意通过 土地价格调节城市用地结构, 刺激第三产业发展, 而 第三产业发展需要大量配套设施建设。与工业用地不 同, 商业用地的配套设施如公园、地铁等与城市居民 日常生活紧密相关, 这些建设投入有利于改善城市公 共服务水平。

政策实施的效果都会因为城市间异质性而不同。 城市间异质性最重要特征体现在城市规模, 而城市规 模又可以分为人口规模和经济规模。人口规模较大的 城市具有明显的资源优势，但“城市病”问题也较为严 重。中国的城镇发展具有政府资源配置的行政中心偏 向特征, 导致中国城镇资源配置严重不均衡, 在行政 配置资源和市场力量的双重极化作用下, 中国大城市 集中了大量的资源、要素和产业, 这种集中又使大城 市政府有能力提供更好的公共服务( 魏后凯, 2014), 但随着城市规模扩大, 城市治理难度也不断增加, 对 城市政府提供公共物品的能力有较大考验。经济规模 是衡量城市经济发展程度重要依据, 也是考核地方政 府官员的重要指标。地方的经济规模越大, 意味着对
地方领导人的治理能力要求相应就越高, 越容易受到 提拔。而相对发展弱势的城市, 领导需要更加努力通 过其他维度考核来获取政绩，弥补 GDP 考核上的劣 势。因此，对不同经济规模的城市而言，地方官员所 受到的晋升激励程度不同，相应地其对待“文明城市” 评选的态度也会存在差异。综上分析, 本文提出假说:

假设 1: “文明城市”评选会改变地方政府公共物 品供给偏好，促进地方基本公共服务的发展，且其可 以财政支出结构、土地价格两个传导途径产生影响

假说 2: “文明城市”评选对不同规模城市的公共 服务提升的效果有显著差异。

\section{2.研究设计}

\section{1.数据来源和样本选取}

考虑到数据可得性和准确性, 本文选择 2009-2017 年中国大陆 102 个地级及以上重点城市作 为研究样本, 共得到 918 个观测值。首先, 通过摘值 法构建城市公共服务指数，相关数据指标来自《中国 城市统计年鉴》、《中国城乡建设统计年鉴》，具体 指标及权重见附表 1 。其次, 截至目前, 中央文明委 共公布了五批全国文明城市，但是前三批“文明城市” 数量较少, 且当时评价体系还不完善, 因此, 为使本 文的分析结果更具代表性，选取入选第四、五批文明 城市且在样本范围内的城市, 作为实验组（43 个）, 其他未拥有“文明城市”称号的城市作为对照组（59 个）。“文明城市”评选的标准十分规范严格，从第四 届开始, 评选以三年评选周期的总成绩作为依据。并 且在入选“文明城市”以后, 中央文明委会对进行不定 期抽查, 要求不符合条件的城市限期整改, 因此形成 的长期性外生冲击可以保证政策效果的稳定与持续。 再次，土地价格相关数据来自《中国国土资源年鉴》 及自然资源部公布的全国主要城市地价监测报告。最 后，经济数据来源于《中国城市统计年鉴》，包括地 级市的人均 GDP、人口、建成区土地面积、第三产 业比重、规模以上的工业企业数量和产值等。参考已 有研究，相关数据均进行了对数化处理。

\section{2. 模型设定}

截至目前, 中央文明委分别在 2005 年、2009 年、 2011 年、2015 年和 2017 年公布了五批全国文明城市。 根据 DID 方法，本文进行如下设置：构建年份虚拟 变量, 把 2009-2011 年间的年份设置为 0, 2012-2017 年间的年份设置为 1 。构建政策虚拟变量, 将 2012 年到 2017 年入选的城市作为实验组, 设置为 1 ; 将 未获得“文明城市”称号的城市作为对照组, 设置为 0 。 根据上述分析，本文设定基准回归模型如下：

$$
Y_{i t}=\partial_{0}+\partial_{1} D I D_{i t}+\partial_{2} D_{i t}+\partial_{3} T_{i t}+\sum \beta_{j} X_{i t}+\varepsilon_{i t}
$$

$i$ 和 $t$ 分别代表城市和时间。 $Y_{i t}$ 为被解释变量, 即 
城市基本公共服务指数。 $D_{i t} 、 T_{i i}$ 分别代表分组虚拟变 量和时间虚拟变量, $X_{i t}$ 代表控制变量。关键解释变 量 $D I D_{i t}$ 代表 $i$ 城市在 $t$ 年是否被评选为“文明城市”。

\section{3.实证结果及分析}

\section{1.基准回归结果：文明城市对城市公共服务 指数的影响}

本文采用了固定效应模型，展示了基准回归结 果。从表 1 结果可以看出, 在不控制城市特征的情况 下, DID 系数为 0.0753 , 在 $1 \%$ 的水平上显著为正, 说明入选“文明城市”后，城市的基本公共服务指数显
著增加。进一步，通过控制模型中的时间效应、城市 特征等相关变量, 双重差分变量系数仍然显著为正, 说明本文选取的控制变量对于城市公共服务指数具 有一定解释力。另外, 本文还使用构成城市基本公共 服务指数的分类指数进行分别回归, 从 DID 系数系 数变化可以看出, 入选“文明城市”对城市教育、医疗、 市民基本生活保障都有正向的影响, 其中对市民基本 生活保障影响最为明显, 对城市基础设施建设有负向 影响, 说明地方政府为了巩固这一成果, 将更多资源 转向了民生型公共物品的提供, 一定程度印证前文关 于政治激励变化会改变地方政府供给偏好的逻辑。

\section{表 1 基准回归结果}

\begin{tabular}{cccccccc}
\hline & $(1)$ & $(2)$ & $(3)$ & $(4)$ & $(5)$ & $(6)$ & $(7)$ \\
& pub & pub & pub & edu & medical & life & infra \\
\hline DID & $0.0753^{* *}$ & $0.104^{* * *}$ & $0.102^{* * *}$ & 0.0197 & 2.174 & 33.43 & -0.326 \\
& $(2.89)$ & $(4.56)$ & $(4.47)$ & $(0.56)$ & $(1.02)$ & $(1.91)$ & $(-0.97)$ \\
控制变量 & & $\mathrm{Y}$ & $\mathrm{Y}$ & $\mathrm{Y}$ & $\mathrm{Y}$ & $\mathrm{Y}$ & $\mathrm{Y}$ \\
Year FE & & & $\mathrm{Y}$ & $\mathrm{Y}$ & $\mathrm{Y}$ & $\mathrm{Y}$ & $\mathrm{Y}$ \\
City FE & $\mathrm{Y}$ & $\mathrm{Y}$ & $\mathrm{Y}$ & $\mathrm{Y}$ & $\mathrm{Y}$ & $\mathrm{Y}$ & $\mathrm{Y}$ \\
常数项 & $0.963^{* * *}$ & $1.695^{* * *}$ & $1.667^{* * *}$ & 1.164 & $132.4 *$ & $1121.4 *$ & $23.40^{* * * *}$ \\
& $(157.61)$ & $(3.62)$ & $(3.62)$ & $(1.62)$ & $(2.36)$ & $(2.39)$ & $(4.30)$ \\
\hline 样本量 & 918 & 918 & 918 & 918 & 918 & 918 & 918 \\
\hline
\end{tabular}

\section{2. 稳健性检验}

参考杨龙见、尹恒 (2015) 的研究, 首先, 将分 组虚拟变量对控制变量进行 logit 回归, 得到倾向匹 配得分, 使用倾向匹配得分最相近的城市作为实验组 文明城市配对后的对照组城市。其次, 在进行 PSM-DID 处理之前, 检验匹配平衡性。利用控制变 量作为协变量, 采用“ $\mathrm{K}$ 近邻匹配法”进行假设检验。 如果匹配后协变量的 $\mathrm{t}$ 统计值均不显著, 则接受实验 组和对照组无系统性差异的原假设; 如果匹配前后标 准偏差的绝对值小于 $20 \%$, 代表匹配处理是有效的。 结果显示, 倾向得分匹配后协变量的离散度下降, 说 明匹配后样本分布相对集中; 另外可以看到绝大部 分样本均匹配成功, 样本量损失不大。上述结果证明 了使用 PSM-DID 方法的合理性。估计结果表明, 使 用 PSM-DID 方法后, 文明城市评选对城市公共服务 指数影响仍显著为正。匹配后样本的回归结果与基准 回归结果相同, 进一步验证了文明城市评选能够促进 城市公共服务水平提升。

\section{3. 机制检验}

基准回归结果显示，“文明城市”评选可以显著的 提升城市基本公共服气水平，但是“文明城市”评选提 升城市基本公共服务水平的具体机制还需要进一步 分析。正如本文第二部分研究假设论述, “文明城市”
评选主要是通过改变地方政府公共物品供给偏好 一体现在财政支出结构变化, 这一途径对城市基本 公共服务水平产生影响。为了检验上述机制, 本文参 考温忠麟（2004）中介效应的检验方法, 在方程 (1) 的基础上进一步扩展为方程（2）和方程（3）。

$$
\begin{gathered}
M_{i t}=\partial_{0}+\partial_{1} D I D_{i t}+\partial_{2} D_{i t}+\partial_{3} T_{i t}+\sum \partial_{j} X_{i t}+\varepsilon_{i t} \\
Y_{i t}=\lambda_{0}+\lambda_{1} D I D_{i t}+\lambda_{2} D_{i t}+\lambda_{3} T_{i t}+\lambda_{4} M_{i t}+\sum \lambda_{j} X_{i t}+\varepsilon_{i t}
\end{gathered}
$$

$M_{i i}$ 为中介变量, 其他变量与方程 (1) 一致。根 据中介效应的检验程序, 依次对方程 (2) 和方程 (3) 进行回归。如表 2 所示, 模型（1）-（2）中 DID 的 系数值显著为正, in_rd 的系数值也显著为正, 说明“文 明城市”评选可以在有效改变地方政府财政支出结构 的基础上，进一步改善城市基本公共服务水平。模型 (3) 中, DID 的系数为正, 模型 (4) 中 Ln_ilp 的 系数为负; 模型 (5) 中, DID 的系数为负, 模型 (6) 中 Ln_ilp 的系数为负 (虽然系数值均不显著, 但是其 通过了 Sobel 检验, 证明了存在中介效应), 这说 明“文明城市”评选亦可以通过影响土地价格, 促进产 业结构转变而进一步改善城市公共服务水平。获得 “文明城市”称号后，城市工业用地价格上涨、商业用 地价格下降，说明地方政府有意通过土地价格调节城 市用地结构, 刺激第三产业发展, 而第三产业发展需 要大量配套设施建设。与工业用地不同, 商业用地的 配套设施如公园、地铁等与城市居民日常生活紧密相 
关，这些建设投入有利于改善城市公共服务水平。另 一方面, “文明城市”评选改变地方政府廉价工业用地 政策，可以更好篮选高质量企业，提高经济发展效率
和质量, 减少环境污染, 这对城市公共服务水平提升 也有正面影响。以上结论对假说 1 作出了很好的验 证。

\section{表 2 中介效应检验结果}

\begin{tabular}{|c|c|c|c|c|c|c|c|c|}
\hline & (1) & (2) & & (3) & (4) & & (5) & (6) \\
\hline & in_rd & pub & & Ln_ilp & pub & & Ln_blp & pub \\
\hline \multirow[t]{2}{*}{ DID } & $0.0966 * *$ & $0.0974 * * *$ & DID & 0.0379 & $0.1000 * * *$ & DID & -0.0132 & $0.103 * * *$ \\
\hline & -2.78 & -4.27 & & -1.31 & -4.32 & & $(-0.22)$ & -4.52 \\
\hline \multirow[t]{2}{*}{ in_rd } & & $0.0428 *$ & Ln_ilp & & 0.0658 & Ln_blp & & 0.0346 \\
\hline & & -2.18 & & & -1.55 & & & -1.51 \\
\hline 控制变量 & $\mathrm{Y}$ & Y & 控制变量 & $\mathrm{Y}$ & Y & 控制变量 & Y & Y \\
\hline Year FE & $\mathrm{Y}$ & $\mathrm{Y}$ & Year FE & $\mathrm{Y}$ & Y & Year FE & Y & Y \\
\hline City FE & $\mathrm{Y}$ & $\mathrm{Y}$ & City FE & $\mathrm{Y}$ & $\mathrm{Y}$ & City FE & $\mathrm{Y}$ & Y \\
\hline \multirow[t]{2}{*}{ 常数项 } & $-6.634 * * *$ & $1.944 * * *$ & 常数项 & $3.908 * * *$ & $1.410 * *$ & 常数项 & 0.312 & $1.657 * * *$ \\
\hline & $(-8.10)$ & -4.18 & & -8.42 & -2.73 & & -0.3 & -3.62 \\
\hline$\overline{\mathrm{N}}$ & 914 & 914 & $\overline{\mathrm{N}}$ & 915 & 915 & $\overline{\mathrm{N}}$ & 915 & 915 \\
\hline
\end{tabular}

\section{4.异质性分析}

根据 2014 年《关于调整城市规模划分标准的通 知》, 以城市人口规模为标准将城市划分为五类, 人 口规模在 500 万和 1000 万之间的城市为特大城 市，人口规模在 100-500 万之间的城市为大城市; 人口规模小于 100 万的城市为中等城市, 城区常住 人口 1000 万以上的城市为超大城市。由于小城市的 样本量太小, 故本文将其剔除。按照不同城市人口规 模分类, 本文在 DID 基础上进行分组回归。回归结 果显示，参与“文明城市”评选，中等城市和大城市显 著的改善了城市公共服务水平, 其中中等城市改善程 度明显大于大城市, 而特大城市、超大城市没有显著 的影响。可能的解释是, 中等城市由于城市规模相对 较小, 虽然资源相对较薄弱, 但其公共服务对象数量 也相应较小, “城市病”问题尚可解决, 城市公共服务 改善难度较低。而且, 正是由于资源有限, 中等城市 政府更有动力通过“文明城市”这一评选，打造城市品 牌, 吸引外界关注, 从而带来资源流入。进一步, 本 文分别以职工平均工资（中位数： 51721.93 元）与人 均 GDP (中位数: 68719.19 元) 作为城市经济发展 的衡量指标, 通过计算中位数对样本进行分组, 将城 市划分为低收入组、高收入组和高经济发展组、低经 济发展组四个子样本集。结果显示, 不论是从工资收 入水平角度还是从城市经济规模角度来看, 发展水平 较低的组在“文明城市”评选过程中, 对城市公共服务 水平提升都相对较高, 体现出“后发优势”。可能的解 释是, 越是经济相对不发达的城市, 在过去“GDP 挂 帅”的考核中越不占优势, 不论是当地官员晋升还是 城市发展需要获取资源, 都处于劣势地位。因此, 在 降低“GDP”比重的新考核体系下, 经济发展水平较低 的城市有非常大的动力参与“文明城市”评选活动。对 于这些相对欠发达的城市，集中资源参评“文明城市”
对于当地官员与居民来说是“双赢”，官员晋升激励与 城市发展目标达到一致。上述结论进一步验证了本文 的假说 2, 即“文明城市”评选的对于城市公共服务水 平的改善, 因城市经济规模的不同而存在显著差异。

\section{5.结论}

本文选择 2009-2017 年中国大陆 102 个地级及以 上主要城市作为研究样本, 并以在样本范围内的 2012 年到 2017 年入选的 43 个“文明城市”作为实验组，以 其他 59 个城市作为对照组, 运用 PSM-DID 方法, 评估了“文明城市”评选对城市公共服务水平影响的 政策效果。研究结果表明: 第一，“文明城市”评选可 以有效改善城市公共服务水平; 第二，“文明城市”评 选可以改变地方政府财政支出结构、影响土地价格, 进一步改善城市基本公共服务水平。第三，城市人口 规模和经济规模对上述政策效应具有显著的异质性 影响。基于上述研究结论, 本文提出如下建议: 第一, 结合我国当下的经济社会可持续发展目标, 重视物质 文明与精神文明同步发展, 为提升人民幸福感和获得 感, 需要地方政府具有更加长远的规划与眼光, 引导 更多资源进入民生领域，对教育、科技等方面进行有 计划、长周期的投资。第二，参评城市要更加严格地 按照“文明城市”评选条件对城市公共基础设施进行 精细化管理与改善, 利用互联网大数据进行城市智能 化管理，积极提升城市生活便利度，减少因资源配置 低效率导致的“城市病”。第三，鼓励更多城市参与“文 明城市”评选，构建良好的竞争环境，以鼓励社会各 界以可持续的眼光看待城市发展，而非仅从经济发展 维度评价城市发展水平。 


\section{REFERENCES}

[1] Lian Zhou. (2007) Governing China's Local Officials: An Analysis of Promotion Tournament Model. Economic Research Journal., 042:36-50.

[2] SY Liu. (2012) Risks and Reform of Land-Based Development Model. International Economic Review, 002: 92-109.

[3] J Li, Q Song. (2018) Land transfer, capitalization and urban infrastructure supply incentives: based on an empirical analysis of 35 large and medium cities in my country. Inquiry into Economic Issues, 006:91-100.

[4] M Wu, Lian Zhou. (2018) Political Incentives and City Construction: The Visibility of Public Projects. Economic Research Journal., 12:99-113.

[5] Lu Jin, Zhao Yanan, Su Yan.(2020)"Civilized City" Selection and Environmental Pollution Control: A Quasi natural Experiment. Journal of Finance and Economics,4:109-124.

[6] H Wei. (2014) Reconstruction of Polarization Tendency and Scale Pattern in the Process of China's Urbanization. China Industrial Economics, 3:18-30.

[7] L Yang, H Yin. (2015) County Government Finance and Expenditure Responsibilities: From the Perspective of the Fiscal Level. Journal of Financial Research,004:82-98. 